\title{
Phytobezoar in a jejunal diverticulum as a cause of small bowel obstruction: a case report
}

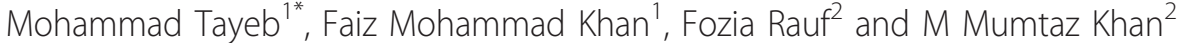

\begin{abstract}
Introduction: Phytobezoars are concretions of poorly digested fruit and vegetable fibers found in the alimentary tract. Previous gastric resection, gastrojejunostomy, or pyloroplasty predispose people to bezoar formation. Smallbowel bezoars normally come from the stomach, and primary small-bowel bezoars are very rare. They are seen only in patients with underlying small-bowel diseases such as diverticula, strictures, or tumors. Primary small-bowel bezoars almost always present as intestinal obstructions, although it is a very rare cause, being responsible for less than $3 \%$ of all small-bowel obstructions in one series. Jejunal diverticula are rare, with an incidence of less than $0.5 \%$. They are usually asymptomatic pseudodiverticula of pulsion type, and complications are reported in $10 \%$ to $30 \%$ of patients. A phytobezoar in a jejunal diverticulum is an extremely rare presentation.
\end{abstract}

Case presentation: A 78-year-old Pakistani man presented to our clinic with small-bowel obstruction. Upon exploration, we found a primary small-bowel bezoar originating in a jejunal diverticulum and causing jejunal obstruction. Resection and anastomosis of the jejunal segment harboring the diverticulum was performed, and our patient had an uneventful recovery.

Conclusion: Primary small-bowel bezoars are very rare but must be kept in mind as a possible cause of smallbowel obstruction.

\section{Introduction}

Phytobezoars are concretions of poorly digested fruit and vegetable fibers found in the alimentary tract [1]. Previous gastric resection, gastrojejunostomy, pyloroplasty, ingestion of high-fiber foods, persimmon fruit ingestion, incomplete mastication habits, and autonomic neuropathies in patients with diabetes are predisposing factors for bezoar formation [2].

Different types of phytobezoars have been reported in the literature. The most common type is the diospyrobezoar, which occurs as a result of the ingestion of persimmons [3]. Pharmacobezoars caused by medicine, shellac bezoars in furniture workers, lactobezoars in neonates, and trichobezoars in psychiatric patients or young girls are other types of bezoars [3,4].

Small-bowel bezoars normally come from stomach, and primary small-bowel bezoars are very rare. They are seen only in patients with underlying small-bowel disease such

\footnotetext{
* Correspondence: drmtayeb@yahoo.com

'Department of Surgery, Peshawar Medical College, Peshawar Medical

College Warsak Road, Peshawar KPK, Pakistan

Full list of author information is available at the end of the article
}

as diverticula, strictures, or tumors [5]. Primary smallbowel bezoars almost always present as intestinal obstructions, although they are a very rare cause, being responsible for less than $3 \%$ of all small-bowel obstructions in one series [6].

Jejunal diverticula are rare, with an incidence of less than $0.5 \%$ [7]. They are usually pseudodiverticula of pulsion type, comprised of only mucosa and submucosa arising from the mesenteric border at vascular entry sites. Despite the fact that most patients with jejunal diverticulosis remain completely asymptomatic, complications are reported in $10 \%$ to $30 \%$ of patients [8-10]. These include chronic abdominal pain, malabsorption, hemorrhage, diverticulitis, bowel obstruction, abscess formation, and, rarely, diverticular perforation [11]. Phytobezoar in a jejunal diverticulum is an extremely rare presentation.

\section{Case presentation}

A 78-year-old Pakistani man was brought to our clinic with a three-day history of epigastric and central abdominal pain associated with vomiting and abdominal distension. He had no history of any loss of weight or appetite. 
He had no significant medical or surgical history, except for recurrent, vague upper abdominal pain for the past few years that was treated as pain related to dyspepsia.

Upon admission, his blood pressure was 130/90 $\mathrm{mmHg}$, his pulse was 100 beats/minute, and he was afebrile. An abdominal examination revealed fullness in the epigastrium and a vague, mobile mass with mild tenderness was palpable in the right hypochondrium. His bowel sounds were sluggish, and rectal examination revealed an empty rectum with no palpable mass. His laboratory investigation results were unremarkable. A supine abdominal X-ray (Figure 1 and 2) showed a dilated jejunal loop in the left hypochondrium. Sonography of the palpable mass was suggestive of a possible abscess cavity with internal echoes.

On the basis of the clinical and radiological findings, a diagnosis of small-bowel obstruction was made. After resuscitation of the patient, an exploratory laparotomy was performed with the interesting finding of a $7 \mathrm{~cm} \times$ $5 \mathrm{~cm}$ jejunal diverticulum arising from the antimesenteric border of the jejunum about $25 \mathrm{~cm}$ distal from the duodenojejunal junction (Figure 3 and 4). The diverticulum was inflamed and full of semi-solid material which was later found to consist of undigested apple pieces with whole maize grains forming a phytobezoar (Figure 5, Figure 6, Figure 7 and 8 . Because of the weight of the diverticulum, the jejunum had twisted at its mesentery, causing obstruction. The omentum was wrapped around the diverticulum, forming a phlegmon. Resection and end-to-end anastomosis of the jejunum were performed. The stomach and the rest of the small-bowel examination revealed no other synchronous phytobezoar.

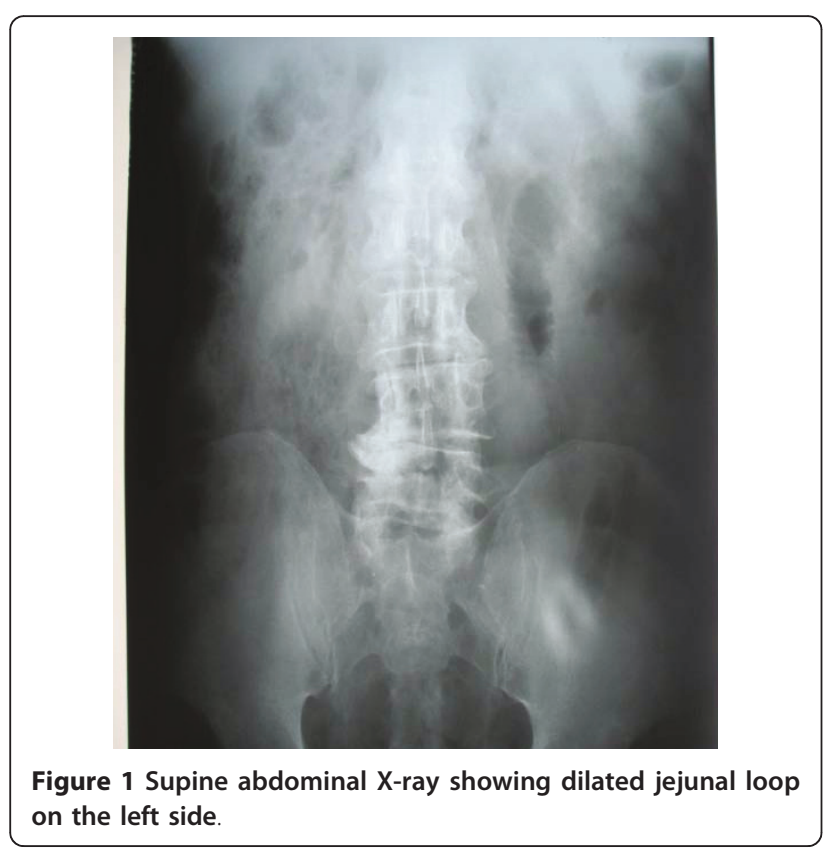

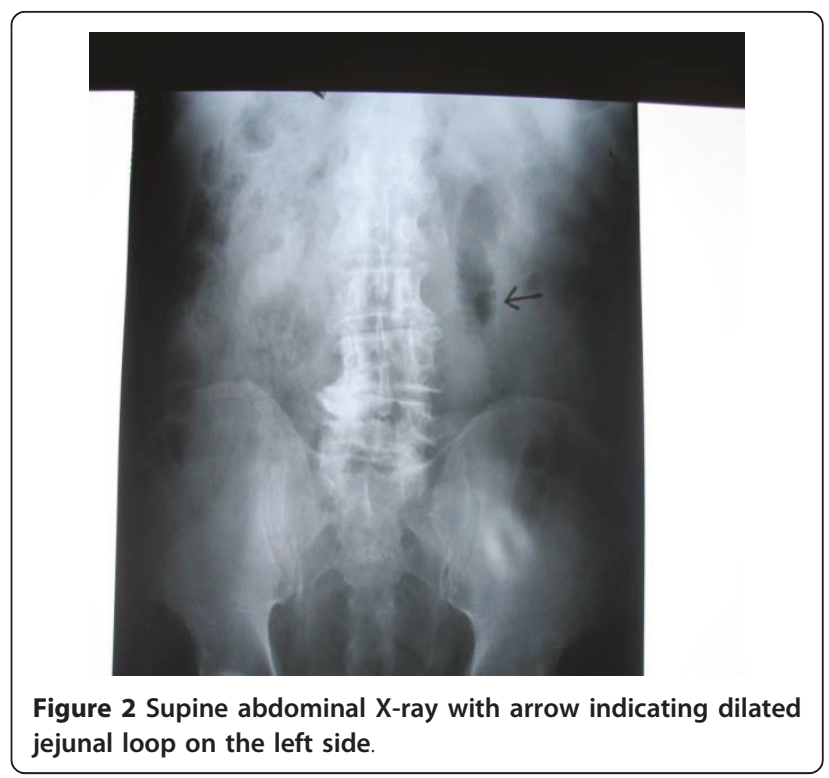

Post-operatively, we noticed that the patient had near total loss of dentition. In response to our inquiry about his dietary habits, he said that he was a fast eater and did not chew food properly, the characteristic feature of an abdominal masticator. The patient had an uneventful recovery.

Histopathology showed a $7 \mathrm{~cm} \times 5 \mathrm{~cm} \times 3 \mathrm{~cm}$ diverticulum arising from the antimesenteric border of the jejunum with marked inflammation and necrosis of the mucosa. This was a true diverticulum containing all the layers. There was no evidence of any malignancy or any ectopic gastric or pancreatic mucosa in the diverticulum.

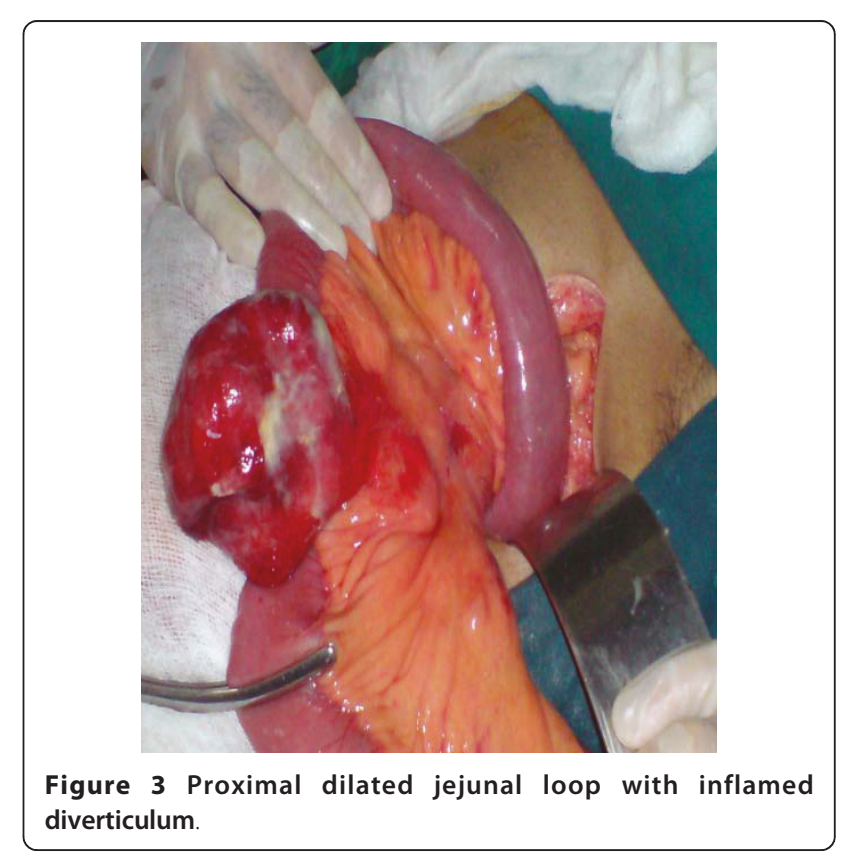




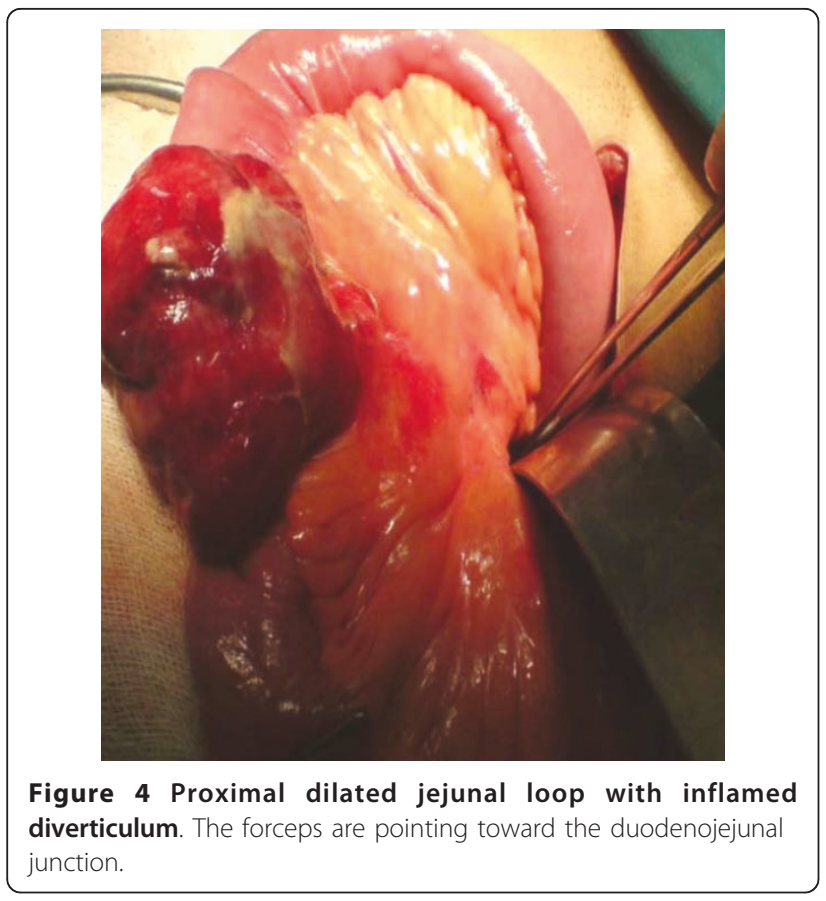

Upon his discharge from the hospital, he was counseled about dietary habits and proper mastication to avoid future problems.

\section{Discussion}

The origin of word "bezoar" derives either from the Arabic term "badzehr" or the Persian word "padzahr,"

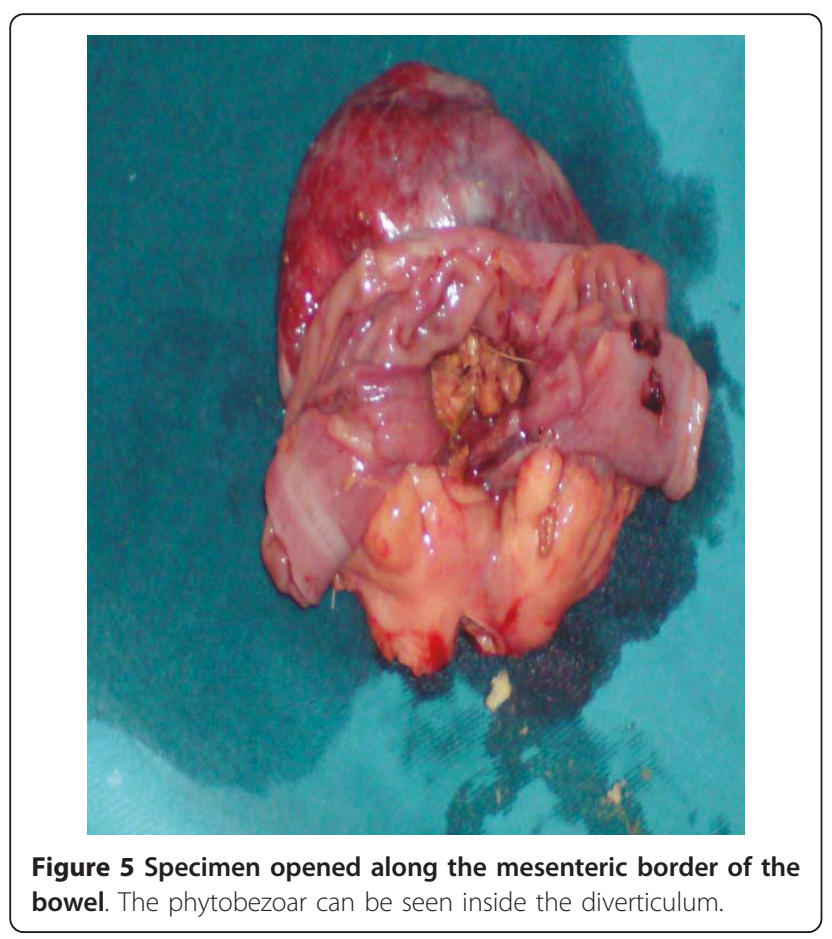

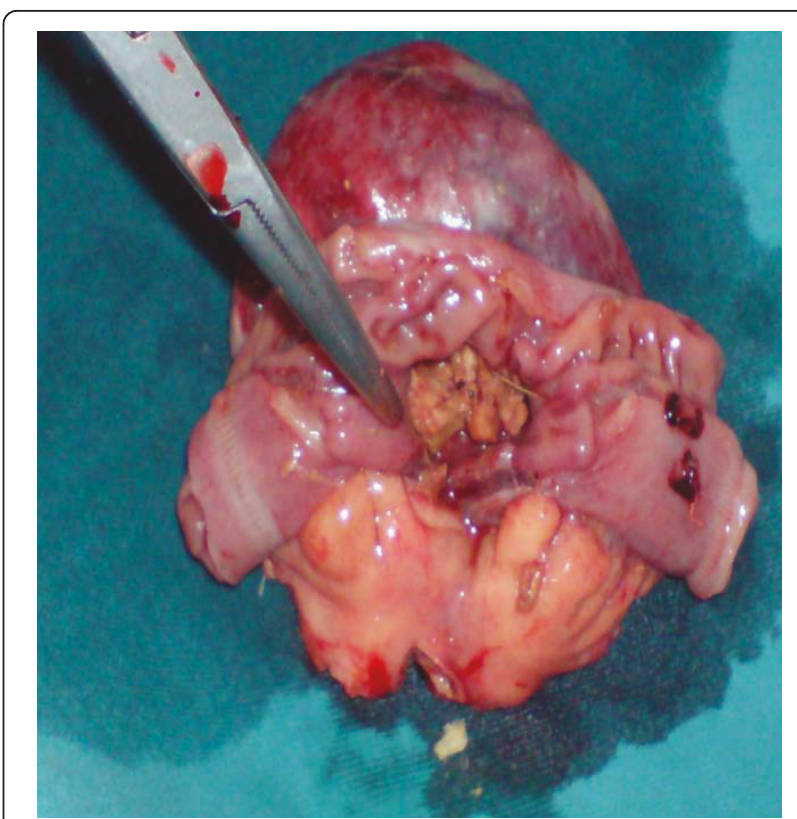

Figure 6 Phytobezoar can be seen inside the diverticulum (pointing forceps)

both of which denote counterpoison or antidote. This word was applied to a greenish, hard concretion found in the fourth stomach of the Syrian goat. The stone was felt to prevent poisoning and came to Europe as the bezoar stone, which was highly prized for its medicinal properties [12,13].

In our patient, abnormal mastication habits as well as a jejunal diverticulum were the precipitating factors for phytobezoar formation that led to small-bowel

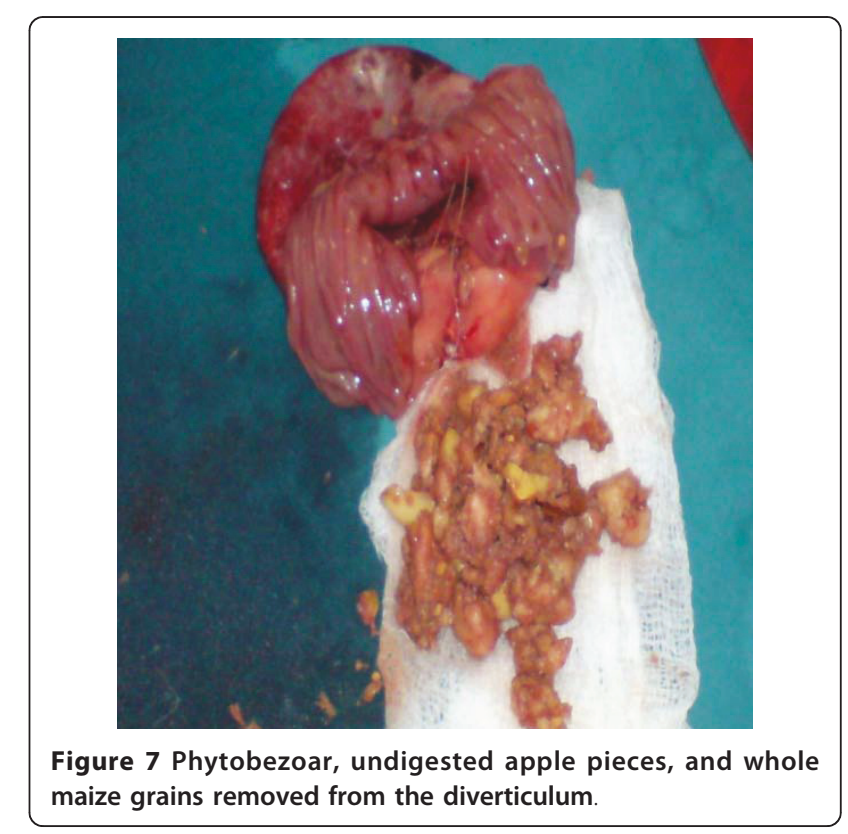




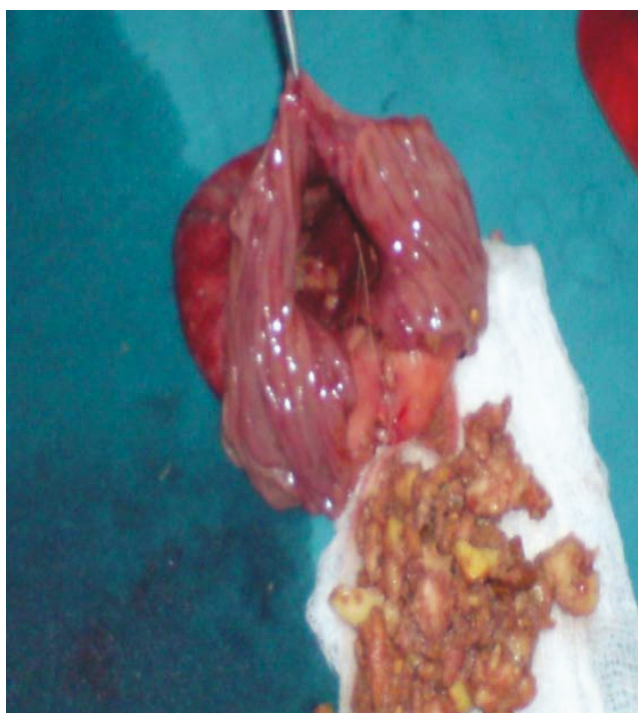

Figure 8 Empty lumen of the diverticulum

obstruction. Although the commonest cause is previous gastric surgery, in our patient there was no such history. Phytobezoars usually occur as single entities, but multiple phytobezoars have been reported in the stomach in $17 \%$ of patients and in the intestine in $4 \%$ of patients $[3,14]$.

Krausz et al. [15] reported a huge increase in the incidence of phytobezoar obstruction in Israel, which was related to the increasing availability and popularity of the persimmon fruit. In Hong Kong, the mid-autumn festival is celebrated in October. During this festival, it is a traditional to eat persimmon fruit. Chisholm et al. [16] reported that two-thirds of the patients in their series presented around this festival time.

Common causes of small-bowel obstruction are adhesions, strangulated hernia, malignancy, volvulus, and inflammatory bowel disease. Phytobezoars are rare, accounting for only $0.4 \%$ to $4 \%$ of all intestinal obstruction. No particular age or sex prevalence has been observed [17]. Primary small-bowel bezoars almost always present as intestinal obstructions.

A number of diagnostic modalities have been used for the detection of abdominal bezoars. Rippolés et al. [18] reported a phytobezoar detection rate of $88 \%$ by ultrasound in patients with small-bowel obstruction. The main limitation of ultrasound is that it is operator-dependent and may be unreliable, as seen in our case. Computed tomography shows the phytobezoars as a mass, a filling defect, or a fecal ball sign [19], which is considered an accurate diagnostic sign in the preoperative diagnosis of phytobezoar.

Small-bowel bezoars are usually treated surgically. It is mandatory to explore the whole gastrointestinal tract to avoid synchronous bezoars and the recurrence of intestinal obstruction due to retained bezoars. Other described treatment options include enzymatic breakdown and endoscopic fragmentation for gastric bezoars $[1,20]$.

In summary, we have described a case of an elderly man with a small-bowel obstruction due to a phytobezoar complicating a jejunal diverticulum. He had a combination of two rarities, that is, jejunal diverticulum and a phytobezoar as a cause of small-bowel obstruction.

A search of the surgical literature revealed only one case of an obstructing phytobezoar arising from a proximal jejunal diverticulum [21].

\section{Conclusion}

Primary small-bowel bezoars are very rare but must be kept in mind as a possible cause of small-bowel obstruction.

\section{Consent}

Written informed consent was obtained from the patient for publication of this case report and any accompanying images. A copy of the written consent (in Urdu) is available for review by the Editor-in-Chief of this journal.

\section{Author details}

${ }^{1}$ Department of Surgery, Peshawar Medical College, Peshawar Medical College Warsak Road, Peshawar KPK, Pakistan. 'Department of Pathology, Peshawar Medical College, Peshawar Medical College Warsak Road, Peshawar KPK, Pakistan.

\section{Authors' contributions}

MT performed the surgery and wrote the main part of the manuscript. FK reviewed the manuscript and made valuable changes. FR performed the histology in this case and also wrote the pathology part of the manuscript. MK performed the histology and revised the manuscript.

All authors read and approved the final manuscript.

\section{Competing interests}

The authors declare that they have no competing interests.

Received: 24 December 2010 Accepted: 27 September 2011 Published: 27 September 2011

\section{References}

1. Acar T, Tuncal S, Aydin R: An unusual cause of gastrointestinal obstruction: bezoar. N Z Med J 2003, 116:U422.

2. Yildirim T, Yildirim S, Barutcu O, Oguzkurt L, Noyan T: Small bowel obstruction due to phytobezoar: CT diagnosis. Eur Radiol 2002, 12:2659-2661.

3. Margolies MN: Foreign bodies and bezoars. In Oxford Textbook of Surgery. Volume 2.. 2 edition. Edited by: Morris PJ, Wood WC. London: Oxford University Press; 2000:1339-1341

4. Zafar A, Ahmad S, Ghafoor A, Turabi MR: Small bowel obstruction in children due to persimmon phytobezoars. J Coll Physicians Surg Pak 2003, 13:443-445.

5. Kim JH, Ha HK, Sohn MJ, Kim AY, Kim TK, Kim PN, Lee MG, Myung SJ, Yang SK, Jung HY, Kim JH: CT findings of phytobezoar associated with small bowel obstruction. Eur Radiol 2003, 13:299-304.

6. Vellar DJ, Vellar ID, Pucius R, Steedman PK: Phytobezoars: an overlooked cause of small bowel obstruction following vagotomy and drainage operations for duodenal ulcer. Aust N Z J Surg 1986, 56:635-638. 
7. Zager JS, Garbus JE, Shaw JP, Cohen MG, Garber SM: Jejunal diverticulosis: a rare entity with multiple presentations, a series of cases. Dig Surg 2000, 17:643-645.

8. Wilcox RD, Shatney CH: Surgical implications of jejunal diverticula. South Med J 1988, 81:1386-1391.

9. Sibille A, Willocx R: Jejunal diverticulitis. Am J Gastroenterol 1992, 87:655-658.

10. Akhrass R, Yaffe MB, Fischer C, Ponsky J, Shuck JM: Small-bowel diverticulosis: perceptions and reality. J Am Coll Surg 1997, 184:383-388.

11. Butler JS, Collins CG, McEntee GP: Perforated jejunal diverticula: a case report. J Med Case Reports 2010, 4:172.

12. DeBakey M, Oschner A: Bezoars and concretions. Surgery 1938, 4:934-963.

13. DeBakey M, Oschner A: Bezoars and concretions. Surgery 1938, 5:132-160.

14. Cuschieri A, Steele RJC, Moosa AR, (Eds.): Essential Surgical Practice: Higher Surgical Training in General Practice. 4 edition. London: Arnold; 2002, 156.

15. Krausz MM, Moriel EZ, Ayalon A, Pode D, Durst AL: Surgical aspects of gastrointestinal persimmon phytobezoar treatment. Am J Surg 1986, 152:526-530.

16. Chisholm EM, Leong HT, Chung SC, Li AK: Phytobezoar: an uncommon cause of small bowel obstruction. Ann R Coll Surg Engl 1992, 74:342-344.

17. Kalogeropoulou C, Kraniotis $P$, Zabakis $P$, et al: Small bowel obstruction due to phytobezoar: CT findings. European Association of Radiology 2003, Clinical case 2840.

18. Rippolés T, García-Aguayo J, Martínez MJ, Gil P: Gastrointestinal bezoars: sonographic and CT characteristics. AJR Am J Roentgenol 2001, 177:65-69.

19. Liou CH, Yu CY, Lin CC, Chao YC, Liou YC, Juan CJ, Chen CY: CT diagnosis of small bowel obstruction due to phytobezoar. J Formos Med Assoc 2003, 102:620-624

20. Andrus $\mathrm{CH}$, Ponsky JL: Bezoars: classification, pathophysiology and treatment. Am J Gastroenterol 1988, 83:476-478.

21. Lough E, Richmond B, Maxwell D, Hayes JD: Obstructing phytobezoar arising from proximal jejunal diverticulum. Am J Surg 2008, 195:106-107.

\section{doi:10.1186/1752-1947-5-482}

Cite this article as: Tayeb et al:: Phytobezoar in a jejunal diverticulum as a cause of small bowel obstruction: a case report. Journal of Medical Case Reports 2011 5:482.

\section{Submit your next manuscript to BioMed Central and take full advantage of:}

- Convenient online submission

- Thorough peer review

- No space constraints or color figure charges

- Immediate publication on acceptance

- Inclusion in PubMed, CAS, Scopus and Google Scholar

- Research which is freely available for redistribution

Submit your manuscript at www.biomedcentral.com/submit 